\title{
FINANCING THE HEALTH CARE IN THE CZECH REPUBLIC: SOME COMPARISONS WITH AUSTRIA
}

\author{
Marie Vavrejnová, Herta M. Rack*
}

\begin{abstract}
:
This paper presents an insight into problems of financing the greatest part of public services for the population - the health care. The situation in this field in two nearby countries - the Czech Republic and Austria is compared.

The health status of the population and the health care bases in both countries are on a high level, and the Czech situation is approaching the somewhat better situation in Austria. The main problem in the both countries is the lack of financial resources for covering the increasing needs in health care services and medicaments. Therefore, the new ways how to balance the deficit of the system both on the revenue and expenditure sides are to be found. The reforms of the system should serve this goal. From the point of view of financial sources for health care a similar model is used in Austria and the Czech Republic, some modifications of it result from different historical development and from different economical level. These modifications and differences, together with the role of the state, insurance funds and direct payments of the population, are described in this paper. The causes of discrepancies between sources of finance and expenditures on the health care are discussed. Reforming the health care system is a long-term task. From this point of view the Austrian reform measures were prepared very well, with the needed advance before introducing them and it can serve as an example for preparation of the Czech reform. Nevertheless, many questions how to improve the financing of the health care for the benefit of patients remain still without answer and they are the matter of further research and discussions in many European countries.
\end{abstract}

Keywords: health care financing, international comparison, resources of finance, reform measures

JEL Classification: I10, I18, I31

\section{Introduction}

Health care represents the greatest part of public services for the population, absorbing in the Czech Republic about 60 per cent of total amount of financial means appointed to the public services, and reaching more than CZK 200 bill. yearly. The amount of the

* Marie Vavrejnová, Economics Institute of the Academy of Sciences of the Czech Republic, Prague (marie.vavrejnova@cerge.cuni.cz); Herta M. Rack, Federal Ministry of Health, Family and Youth, Austria.

This research was undertaken with support of the Grant Agency of the Czech Republic No. 402/04/0025. 
health care expenditure continues to grow and this growth is faster than the growth of GDP in all developed countries, what causes the strain in financial balance of this branch. This is the reason why many countries have dedicated recently particular attention and effort to resolve the problems of health care financing.

The exceptional importance of the health care is given by the matter it deals with, i.e. the health of the population, which is the most important value of the human life. In this paper, we try to compare the economic situation of health care in the Czech Republic and Austria. We chose the comparison of these two countries for many reasons. They are neighbouring countries with similar territorial size and with similar number of inhabitants. The area of Austria is $83,871 \mathrm{~km}^{2}$, that of the Czech Republic is $78,866 \mathrm{~km}^{2}$, the number of inhabitants in Austria in 2005 was 8.118 million, that of the Czech Republic 10.234 million. They both are open economies with intensive mutual relations and economic cooperation, which have been intensified in the framework of European Union. Moreover, both countries were parts of a common state in the distant past, with tight-knit cultural and social relations. The common history is hitherto noticeable in both countries. However, there is still a significant difference in the economic level of Austria and the Czech Republic, caused by the lag of the development during the totalitarian regime which ruled in the Czech Republic for forty years. In 2005, measured as GDP per capita in current PPPs, the level of the Czech Republic was $60.1 \%$ of the Austrian level, and $67.6 \%$ of the EU - 15 average ${ }^{1}$. This demonstrates also, that Austria is a developed country with higher economic level than the average of the EU -15 . This economic position influences also the situation in the Austrian health care system, which has more financial means at disposal. Austria therefore, can serve as a hypothetical picture of the Czech future and its experience is useful to study. Unfortunately, the international comparison suffers from the delayed supply of statistical data more than the national statistics and so we cannot show the last years' development trends in general, and in our case the growth of GDP expressed in comparable figures in particular. But we know from the national statistical data that the growth of the economy of the Czech Republic is especially in last years faster than that of Austria and the difference in economic level of both countries is gradually diminishing. Let us hope that this trend will continue.

A further reason for comparison with Austria is the more advanced and more in details developed Austrian health care reform. The Austrian experience in providing reform measures in this field may be important for the Czech Republic even if we take into consideration that every country has its specific conditions and specific requirements for providing the system of reforms which cannot be plainly transferred to another country.

The possibilities of international comparison in the field of health care are considerably limited due to difficulties in measuring both the quantity and quality of health care services. It results from specific features of this branch. The relations between providers of the health care - the doctors- and users of it - the patients - are very responsive and have quite individual character, resulting from different health situation of the patient,

1 Source of data: OECD Factbook 2006. 
different kinds of diseases, different personalities of the patients and doctors. The specific orientation of these services - on the health of the population - requires highly ethical approach in dealing with all problems.

Nevertheless, the main quantitative indicators, giving a picture about the health status of the population, about organization of the health care, about performance of health care, and about amounts of financial means allocated in this branch, are relatively well comparable and are also the matter of international statistics.

Health care statistics and analytical studies' number has recently very much expanded in connection with discussions on the needed reforms, and bring a lot of information for everybody who is interested in this field. The following overview of some selected indicators should give a picture of similarities and varieties of the situation in health care of compared countries. Let us compare firstly some selected indicators, characterizing the health status of the population and health care personal and material bases.

\section{Selected Indicators in the Field of Health Care}

\subsection{The Health Status of Population}

Let us demonstrate the health status of population with following selected indicators and their development during the decade 1995 - 2004:

\begin{tabular}{rcccr} 
& \multicolumn{2}{c}{ Austria } & \multicolumn{2}{c}{ Czech Republic } \\
Life expectancy at birth (years) & Women & Man & Women & Man \\
2004 & 82.1 & 76.4 & 79.0 & 72.6 \\
1995 & 79.9 & 73.3 & 76.6 & 69.7
\end{tabular}

Fertility rate (children per women 15 - 49)

$\begin{array}{ccc}2004 & 1.42 & 1.22 \\ \text { Infant mortality (per 1,000 live birth) } & & 3.7 \\ 2004 & 4.5 & 7.7 \\ 1995 & 5.4 & \end{array}$

Mortality cause (in percentage of all deaths, three main kinds):
Malignant neoplasm
23.8
26.3
Circulatory system
54.3
53.4
Respiratory system
4.6
4.5

Life expectancy in both countries is continuously increasing, nevertheless in Austria it is now more than three years higher, similar to the EU 15. Fertility rate in the Czech Republic has been very decreasing in recent years and now it is the lowest among all by OECD observed countries. This is together with the growing life expectancy the main reason of population ageing. Only in 2005 it improved a little and let us hope that it will be also a future tendency. In Austria, the fertility rate is on the average level of European 
countries, which is 1.40 . Infant mortality belongs in both countries to the lowest among 20 observed OECD countries. The introduced structure of main mortality causes is similar in all EU countries.

Furthermore, we introduce the comparison of the value of three non-medical factors that influence the health and cause the growth of health expenditure. The data are for the year 2003:

Percentage of Obesity of Population (Body Mass Index - BMI $>30^{2}$ ). Obesity is a risk factor for several diseases. It jeopardizes now also a sizeable part of children, which will cause them health complications in adulthood.

In Austria in 2003, the rate of obesity was both for men and women $9.1 \%$, in the Czech Republic $13.4 \%$ for men and $16.1 \%$ for women. The highest percentage of obesity is in the USA, $27.7 \%$ for men, and $34.0 \%$ for women and therefore there exists a strong endeavour to improve this situation. A recent study estimated that the costs related to obesity exceeds now the costs related to smoking and drinking for a set of chronic health problems ${ }^{2}$.

Percentage of Adult Population Smoking Daily. In 2002, $24 \%$ of the adult population of the Czech Republic were smokers. It is among countries with the lowest share of smokers (Canada and the United States with the share of 17 and $18 \%$ ), and countries with the highest share (Hungary and Greece, with the share of 34 and $35 \%$. Unfortunately, in the Czech Republic the number of smoking children under 15 years old increases and the percentage of smokers is in reality higher. The numbers of smokers in Austria are not at disposal.

Alcohol Consumption in litres per capita for Population in Age Category 15 Years and Older. In 2003, it was 11.1 in Austria, while 12.1 in the Czech Republic. Both countries belong to the group with high consumption of alcohol. Unfortunately, the experience shows that also children under 15 consume alcohol and their number is growing.

These bad habits of the significant share of population (overeating, smoking and excessive drinking of alcohol) result in many diseases, which cause growth of health care expenditure. Therefore, it is quite right to procure more financial means by higher taxation on consumption of these products.

\subsection{The Health Care Personal and Material Base}

\section{Personal Base of the Health Care}

Both in Austria and in the Czech Republic, the basis of the health care is on a high level. The number of inhabitants per 1 doctor in Austria reaches 226, in the Czech Republic 250. The whole number of doctors in the Czech Republic in 2005 was 40,802, in Austria (the last data for 2003) 37,447. The significant difference is, however, in the share of men and women among doctors: the share of women in the Czech Republic is $55.4 \%$, in Austria $37.5 \%$. Altogether, in 2002 there worked in the Czech health care sector about 255 thousands of persons, of them $79.6 \%$ women.

2 See "Health at a Glance" OECD Indicators 2005, page 86. 
It is worth to deal here with the differences in remuneration in health care sector in compared countries. The level of salaries and incomes in general is an important part of total health care costs, with great cross-country differences, that can influence the migration of professionals, and their surplus or shortage in a country. The OECD data introduce the comparison via the ratio of remuneration per year to GDP per capita. The great differences in country methodologies (the unified methodology does not exist) cause difficulties and great uncertainty in cross-country comparison. ${ }^{3}$ But the main contour of differences among countries is given. The ratio of the remuneration to GDP per capita in the sector of health care in the Czech Republic is the lowest among compared countries, followed by Hungary (unfortunately the data for Austria are not introduced). In some countries like the Netherlands, the Unites States, Belgium, Germany and others the incomes are many times higher. This is valid for both self-employed and salaried, for specialists and general practitioners and also for nurses. It confirms the opinion that the good results of the Czech health care are sponsored by low remuneration of doctors and nurses.

From national statistics it is possible to introduce data comparable only within the country with other sectors of the national economy, which are not directly comparable across countries. The general model of remuneration in Austria and the Czech Republic is the same: the highest remuneration in banking, the lowest in textile, while the remuneration in health care reaches the middle values.

In Austria ${ }^{4}$ the salaries and other incomes (incomes of self-employed doctors, of nurses, etc.) differ according to regions (the health care in Austria is highly decentralised and the comparison is difficult also for many other reasons. For instance, the payment level of doctors in public hospitals is lower than in private sector - on the contrary to the Czech conditions - and to keep doctors in the public sector, they are allowed to treat private patients in public hospitals to earn additional income). The level of additional income depends in this case on the number of special class beds in the department. But this may not exceed $25 \%$ of the total bed capacity. In any case, it can lead to incentive to keep higher number of beds, what is against the effort to lower the number of them.

According to estimates of the Austrian Physicians' Chamber, the gross initial salary for doctor amounts to about 50,000 euro per year, and after ten years' experience he can get 75,000 euro. The average income of self-employed doctors in the third income quartile amounted per year to 141,051 euro, but the male doctors earn much more than female $(178,652$ per year in the third income quartile). At about $50 \%$ of this income in average covers the costs of overheads (salaries of employees - nurses, receptionists-rent, electricity, etc.).

In the Czech Republic, the employees of state-subsidised organisations and government organisations, who represented about $50 \%$ of the employees in health care, received in 2005 the average monthly salary CZK 19,833, the salary of doctors including dentists was CZK 38,668 and that of nurses and midwives CZK 18,787, it means about $50 \%$ of the remuneration of doctors. The remuneration in private health establishments founded by a physical body and other non-government legal bodies was

3 For details see "Health at a Glance", OECD INDICATORS 2005, pages 42, 43.

4 Source: "Health Care System in Transition" 2006, Ministry of Health, Family and Youth. 
by almost 3 thousand korunas lower, what means by about $14.5 \%$ lower than the total average wage in the national economy. However, the last increases of the salaries of doctors discourage the emigration of them, in particular of the specialists to Western countries, in connection with the higher living costs in these countries. In another situation are young doctors and nurses with low wages. Therefore, especially in cross-border regions there is lack of them.

The questions of the health care remuneration themselves calls for a special study which would try to gather and complete more information enabling better international comparison in this field.

\section{The Material Base of Health Care}

The Czech statistics presented the whole number of hospitals in 2005: 195, and the number of beds in hospitals - 64,174. Related figures for Austria are 112 hospitals and 44,059 beds.

The number of beds is steadily decreasing in both countries.

Average length of stay in hospitals in the Czech Republic is 11.1 days, in Austria 8.1 days, which is an average rate among European countries. (The extremely high indicator is in the Netherlands, namely 33 days). In Austria and CR, there exists the effort to reduce the number of beds and the number of days in in-patient care. This is one of ways how to economize financial expenditure in health care. Also the number of hospitals has to be reduced. But here it is necessary to take in mind the needs of patients in order not to worsen the access to health care.

In the Czech Republic, there were 2,350 pharmacies, in Austria 2,221. Their number both in the CR and Austria is growing. A few comparable data published about number of medical equipment for diagnostic and therapeutic purposes show a worse situation in the CR than in Austria. We introduce comparison of the number of three groups of medical apparatuses per million population, in 2002: Computer tomography scanners: Austria 27.2 pieces, CR 12.3; Magnetic resonance scanners, which are newer technology without ionising radiation: Austria 12.5, CR 2.2; Austria is in a better position not only in comparison with the $\mathrm{CR}$, but also in comparison with the average of observed OECD countries. Only in radiotherapy equipment is in a better position the CR: Austria 6.7, CR 12.3 pieces.

In general, introduced data testify somewhat better situation in the health status of the population and in the base of the health care in Austria in comparison with that in the Czech Republic. Nevertheless, this difference is not in concordance with the well - known good results of the Czech health care on the one hand and with the great difference in the total amount of financial means appointed to health care in the Czech Republic and Austria, which reached in 2004 only $43.6 \%$ of the Austrian level, as shown here below. There seems to be two main factors influencing this difference: the higher level of modern medical technologies in Austria shown above, which are expensive and represent one of main factors rising the cost of health care. Another factor seems to be already mentioned - great difference in payment of doctors and nurses in Austria and the CR. 


\section{Health Care Expenditure and Sources of Financing the Health Care System}

\subsection{Health Care Expenditure}

The most general indicator used for comparison the health care expenditure across countries is expenditure per capita converted from national currency units to US dollar taking into account differences in the purchasing power of national currencies, it means calculating USD purchasing power parity (USD PPP). Further, taking into account different economic level of the compared countries, the indicator expenditure in USD PPP in relation to gross domestic product (GDP) for comparison across countries is used. This indicator is growing in long-term in most of countries. ${ }^{5}$ The difference between Austria and the Czech Republic remains at about one percentage point.

Comparing the total health care expenditure per capita in USD PPP in the last ten years we notice substantially higher amount in Austria ${ }^{6}$ :

Table 1

Expenditure on Health Care per Capita in USD PPP

\begin{tabular}{|l|c|c|c|c|}
\hline \multirow{2}{*}{} & \multicolumn{2}{|c|}{ Total expenditure } & \multicolumn{2}{c|}{ \% of the GDP } \\
\cline { 2 - 5 } & $\mathbf{1 9 9 5}$ & $\mathbf{2 0 0 4}$ & $\mathbf{1 9 9 5}$ & $\mathbf{2 0 0 4}$ \\
\hline Austria & 2,229 & 3,124 & 8.0 & 9.2 \\
\hline Czech Republic & 902 & 1,361 & 7.0 & 7.3 \\
\hline
\end{tabular}

Even if the amount of expenditure in the Czech Republic increased more than in Austria (by $50.9 \%$, and in Austria 40.1\%) it was in 2004 only $43.6 \%$ of the Austrian level. (The highest sum for health care is spent in the USA, where it reached in 2004 USD 6,102 per capita, which means 4.5 time more than in the Czech Republic).

A notable difference we find in the share of public and private expenditure: in 2004 the share of public expenditure in Austria was $70.7 \%$, while in the Czech Republic $89.2 \%$, what seems to testify a very low participation of the population in direct payments for health care, and it is really (together with Luxembourg) the lowest among OECD countries. But in comparison with Austria, there are in the CR much higher rates of insurance contributions. The share of private payments is growing more quickly in the CR than in Austria, where since 1999 is even decreasing. The share of $25.1 \%$ reached in 2004 seems to be satisfactory. The share of private expenditure in the Czech Republic is far from this value. The following time series show the growing trend of means appointed to the health care in the Czech Republic and more stable development in Austria, caused by the higher absolute level of means reached during the past development (the following data are introduced in national currency and current prices):

5 Using this indicator we find many differences in different sources, and different time. It is due to frequent re-counting of the value of GDP (the indicator of expenditure is more stable) and due to different methodology. The last value of the indicator EXP/GDP for Austria due to new methodology is for the year 2004 higher, namely $9.6 \%$.

6 Source: "OECD in Figures, 2006 - 2007 Edition". 
Table2

Development Trends of the Public and Private Expenditure on Health Care, 1995 - 2005 $(1995=100 \%)$

\begin{tabular}{|l|c|c|c|c|c|c|c|}
\hline & $\mathbf{1 9 9 5}$ & $\mathbf{2 0 0 0}$ & $\mathbf{2 0 0 1}$ & $\mathbf{2 0 0 2}$ & $\mathbf{2 0 0 3}$ & $\mathbf{2 0 0 4}$ & $\mathbf{2 0 0 5}$ \\
\hline Public expenditure & 100 & 138 & 143 & 149 & 154 & 162 & . \\
\hline Private expenditure & 100 & 145 & 153 & 151 & 158 & 163 & . \\
\hline \multicolumn{7}{|c|}{ Czech Republic } \\
\hline Public expenditure & 100 & 141 & 158 & 168 & 184 & 193 & 208 \\
\hline Private expenditure & 100 & 148 & 171 & 191 & 224 & 238 & 292 \\
\hline
\end{tabular}

Source: Czech Health Statistics 2005, UZIS, Prague; Health System in Transition 2006, Bundesministerium für Gesundheit, Familien und Jugend.

Figures to the Table 2
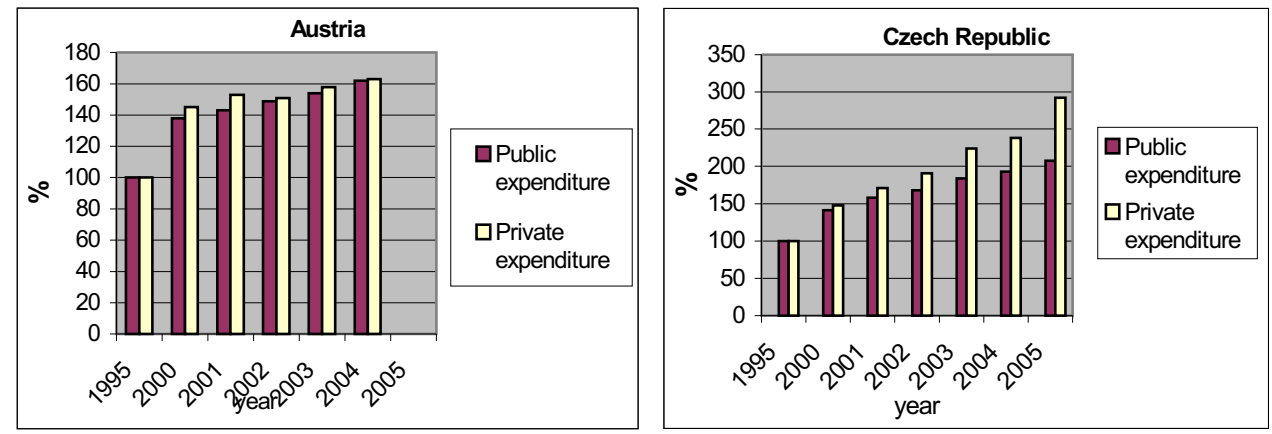

(Pay attention to different percentage of the y axis)

\subsection{The Structure of Financial Sources for Health Care Sector}

The key role in gathering and distribution of the financial means belongs to insurance funds, established in the Czech Republic only in the first half of ninetieth. Their number has gradually stabilized on 9. In Austria, there operate 21 insurance funds, 9 of them on the regional level, because the majority of health care services is organized and managed by regions (Ländern). The role of insurance funds is in the Czech Republic yet under discussions and research. Purely economically taken, there is no difference between the finance for health care from public budgets and public insurance funds. The both parts are in fact taxes. (This is indirectly expressed also in subsidies which the greatest Czech insurence fund received for covering its financial deficit). The introduction of insurance funds should promote the competition in providing the health care and as a consequence to improve the health care for patients and at the same time to improve the efficiency in exploitation the resources. In theory, the pluralistic system should have better conditions for performance of these functions. But it is necessary to weigh the raised costs of this system with the benefits it brings. But how to measure the benefits? Besides, the incomes of the insurance funds are redistributed due to different structure of the patients and their incomes. (This is the result, among others, of the concrete age structure of the insurers, where at the General Insurance Fund the share of 
elderly is the highest). The administrative role of the funds still quite prevails. There are not great differences in proposed services of the insurance funds. Therefore, the question of the system of only one insurance fund emerges again in political debate. And on the other hand, the patients have not got the needed information about the functioning of the insurance funds and about the possibilities of choice among them. The majority of patients remain at the General Health Insurance Company. However, their number decreased last ten years from 7.8 mill. in 1996 to 6.7 mill. in 2005 in connection with growing financial deficit and other difficulties in accounting of this insurance fund. The main impulse for changes in patients' membership have come from the doctors themselves who adviced to change the insurance fund (the personal experience of the Czech author) due to delayed payments for them from this insurance fund. More than ten years after introduction of the pluralistic system, very little have been done for improvement of its behaviour. So far there does not exist an appropriate information for the patients about activities of the insurance funds, the results of their housekeeping and the activities and results of supervision are not available for the public. Under these conditions the patient cannot decide about the best insurance fund for himself. Also the analytical studies about different systems of insurance which could operate in Czech conditions do not exist. In short, the first condition for well operating system of health insurance - the necessary information - is not yet at disposal. Therefore, the further reform steps pursue the improvement of the activities of insurance funds and the main problems of their functioning remain to be solved in the future.

Table 3

The Structure of Financial Resources for the Health Care

\begin{tabular}{|l|c|c|}
\hline & Austria & Czech Republic \\
\hline Total & 100.0 & 100.0 \\
\hline Insurance funds & 45.3 & 79.1 \\
\hline Public budgets & 25.1 & 8.1 \\
\hline Private & 25.0 & 12.8 \\
\hline
\end{tabular}

Source: Health System in Transition 2006, Bundesministerium für Gesundheit, Familien und Jugend, Wien; Health Care Statistics 2005, UZIS, Prague.

The table demonstrates not only the prevailing role of insurance funds in the structure of financial sources for health care in the Czech Republic, but also hitherto a significantly lower share of private expenditure in comparison with Austria. The private expenditures in Austria are divided into three groups, which are statistically observed: direct cost-sharing ( $57.6 \%$ from the total sum of private expenditure), which includes fees for services, e.g. prescription fees, then percentage co-payments for civil servants, self-employed and employees of Austrian Railways (as a survival of privileges of these groups of employees); indirect cost-sharing (32.3\%) which includes expenditure on services and products which are not included in catalogues of the health insurance funds; the third group is private health insurance (10.1\% in the year 2004). Around a third of the Austrian population has private voluntary (supplementary) insurance. It mainly covers costs of better accommodation and special treatment by non-contracted doctor. 
The decisive part of the insurance expenditure are routed through insurance funds into the following structure:

Table 4

Expenditure Structure of the Insurance Funds for Health Care

\begin{tabular}{|l|c|c|}
\hline & Austria 2004 & CR 2005 \\
\hline Total & 100 & 100 \\
\hline Out-patient care & 23.3 & 23.1 \\
\hline In-patient care & 38.9 & 46.7 \\
\hline Prescribed medicaments and medical aids $^{7}$ & 17.1 & 25.4 \\
\hline Other, non specified $^{7}$ & 20.7 & 4.8 \\
\hline
\end{tabular}

Source: Health System in Transition 2006, BMGFJ, Wien; Health statistics 2005, UZIS, Prague.

The high share of medicaments in the Czech Republic is one of the most burning themes of discussed reforms of the health care system.

Table 5

Development of the Volume of Distributed Medicaments

\begin{tabular}{|l|c|c|c|c|c|c|c|c|c|c|c|c|}
\hline & $\mathbf{1 9 9 1}$ & $\mathbf{1 9 9 5}$ & $\mathbf{1 9 9 6}$ & $\mathbf{1 9 9 7}$ & $\mathbf{1 9 9 8}$ & $\mathbf{1 9 9 9}$ & $\mathbf{2 0 0 0}$ & $\mathbf{2 0 0 1}$ & $\mathbf{2 0 0 2}$ & $\mathbf{2 0 0 3}$ & $\mathbf{2 0 0 4}$ & $\mathbf{2 0 0 5}$ \\
\hline $\begin{array}{l}\text { Bill CZK, Index } \\
(1990=100)\end{array}$ & 111 & 409 & 449 & 479 & 531 & 581 & 612 & 706 & 766 & 833 & 909 & 1030 \\
\hline $\begin{array}{l}\text { DDD/1000/d, } \\
\text { Index }(1990=100)\end{array}$ & 78 & 109 & 114 & 121 & 126 & 136 & 137 & 144 & 147 & 153 & 155 & 176 \\
\hline
\end{tabular}

Introduced data show that quickly growing volume of distributed medicaments was caused especially by huge price increase, because their consumption in DDD/1000/d increased during last 17 years only by $76 \%$ and their value increased ten times.

Figure to Table 5

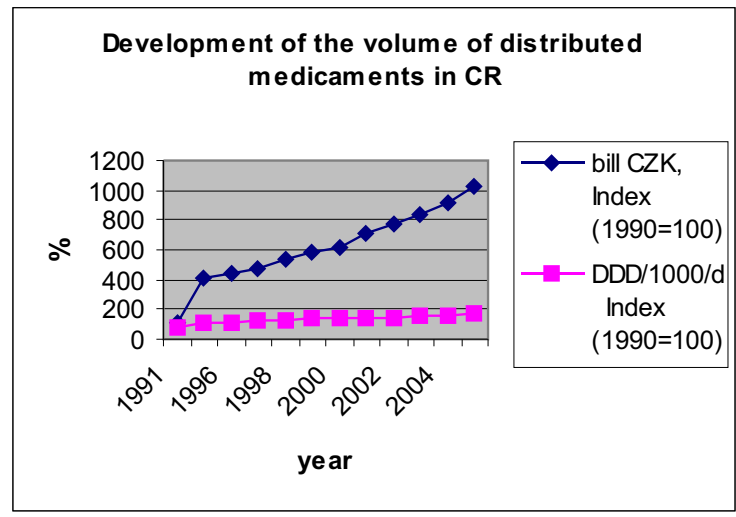

7 In the Czech Republic: Costs of balneal care, treatment abroad, transport, medical emergency service, care in convalescent homes and other health care.

8 DDD/ $1000 \mathrm{~d}=$ Defined daily dose per habitant and day. 
Especially the imported medicaments (the share of Czech origin distributed medicaments is only about $36 \%$ ) heightened the price level.

In Austria, the share of expenditure on medicaments amounts to $17.1 \%$, it means significantly less than in the Czech Republic. The economy of expenditure on medicaments which are financed by insurance institutions in Austria (their share in all consumed medicaments reaches at about three quarters of the total expenditure) is appointed in the General Social Insurance law. Nevertheless, the number of prescriptions on the account of health insurance companies has grown since 1990 in average by $2.5 \%$ per year, but the expenditure from the sources of the health insurance for medicaments grew four times more than the prescriptions. But the total expenditure on medicaments grew more quickly, what means that the share paid by patients from their pockets increased. In general, the increase of financial expenditure on remedies in Austria goes, like in the Czech Republic, but also in all other countries, on the account of the rise of their prices ${ }^{9}$. It is a general tendency and there are different causes of it. The process of innovations in the field of remedies is one of them and the pharmaceutical firms justify the increase of prices by it. Another reason for the high increase is the specific character of the pharmaceutical goods, the patient is depending more on the doctors and pharmacists than on his own choice and very often it happens that doctors and pharmacists are interconnected with the pharmaceutical firms which does not enable the enforcement of the market price. Also, the specific character of costs structure of the pharmaceutical production causes a relatively high monopolization of the production, which allows the growth of prices. It is assumed that the slowdown of prices of remedies in Austria should be achieved with the help of obligatory preference of prescription generica, than in decreasing the surcharge (in the Czech Republic it comes to $20 \%$ and its decrease should be also one of the factors of lowering the price of drugs), further in decreasing the taxation of medicaments which is in Austria much higher than in the CR (the rate of taxation of them in Austria is $20 \%$, in the Czech Republic $9 \%$ ). A very important factor is the control of the economy of prescribed remedies by doctors from the part of health insurance funds, which is anchored in the general law of the health insurance. For the observance of it doctors in Austria have personal responsibility and in case of overdrawing certain limits they are penalized.

\subsection{Private Payments of Population for Health Care and Their Impact on the Structure of the Expenditure of Different Types of Households}

The theme of private payments for health care is one of the most discussed problems of the health care reforms in CR, especially in political circles.

Compared with the initial year 1991 when the amount of direct personal expenditure was insignificant, it increased to the year 200312.4 times. That increase was reflected in different types of households variously, the most in households of pensioners, where the amount of direct payments from their pockets increased in the period of $1989-200218$ times, included the expenditures for remedies, which increased 29 times. The expenditure in the households of employees increased 20 times, and for remedies 33.7

9 Statistical data show that in the period 1998 - 2002 the pack of medicines per inhabitant grew by $9.3 \%$, and their value by $23.4 \%$. Source: Health System in Transition. 
times (see introduced graphs). But anyhow high the figures and their growth seems to be, it is due to very small initial amounts at the beginning of the transition of the Czech economy, and in the structure of the household's expenditure they have even in 2004 a very low share. As an example we introduce the cases of the households of employees and the households of pensioners.

Table 6

Expenditure per Capita of Average Household

(per year, in CZK)

\begin{tabular}{|l|c|c|c|}
\hline & 1990 & 1995 & 2004 \\
\hline Households of employees & 37 & 474 & 1145 \\
\hline Pharmaceutical & 40 & 220 & 299 \\
\hline Health and social care & 74 & 639 & 1936 \\
\hline Households of pensioners & 87 & 289 & 550 \\
\hline Pharmaceutical &
\end{tabular}

Sources of data: Czech Statistical Office.

Figures to Table 6
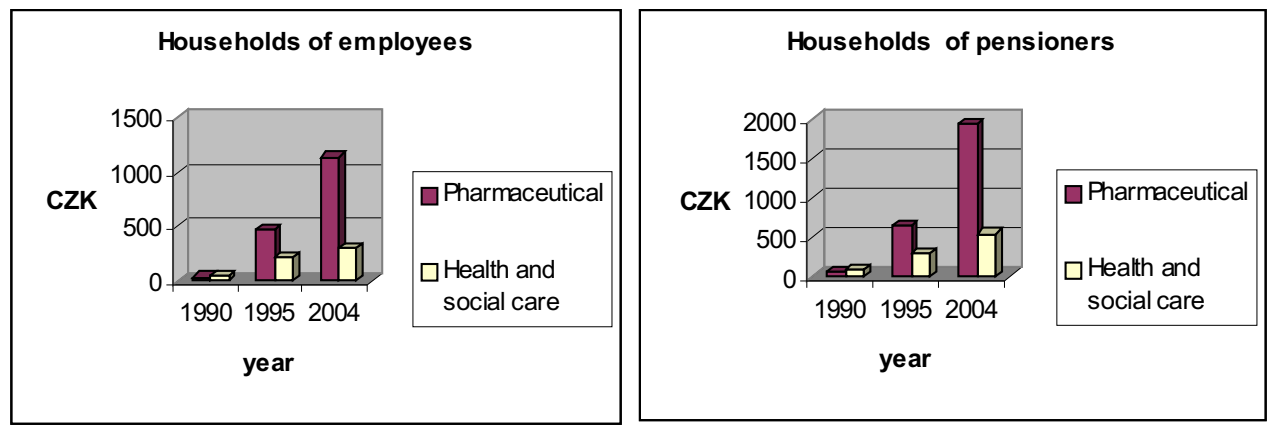

(Pay attention to values of axis y)

The data show higher growth of the pensioners' expenditure. Since the here introduced year 2004 the expenditure of households has grown furthermore, of course. Progresively there have grown the expenditure on pharmaceuticals as consequence of growing prices while the health and social care remained in quite prevailing part paid as public service by the insurance institutions.

However, the average amount of private personal expenditure tells very little about the amounts of expenditure of a concrete type of households, it is necessary to take into account the income inequality. There are both poor households of employees and rich households of pensioners. Different income cohorts of the population have different volume of the expenditure. In our case the difference between the first and the fifth quintile of the household of employees is about $400 \%$ of the value of expenditure on health care, and of the household of pensioners it is about $150 \%$. This problem requires special analysis, which is not the matter of this article.

In spite of quick growth of private personal expenditure on health care its share ( $8.4 \%$ in 2003$)$ is much lower than in most developed countries. But the figures are 
incomparable from the point of view of total expenditure on health care paid by the population due to different percentage of health insurance contribution in different countries. In the Czech Republic, this percentage in relation to gross wages and salaries is significantly higher than in Austria. Also the rate for the employee and employer is quite different. The Czech employer is more taxed in comparison with the Austrian one.

Table 7

The Rates of the Health Insurance Contributions (\% of the gross income)

\begin{tabular}{|c|c|c|c|c|c|}
\hline \multicolumn{2}{|c|}{ Czech Republic } & \multicolumn{2}{c|}{ Austria } \\
\hline Total & \multicolumn{2}{|c|}{ Paid by: } & Total & \multicolumn{2}{c|}{ Paid by: } \\
\hline & Employee & Employer & Blue collar & Employee & Employer \\
\hline 13.5 & 4.5 & 9.0 & 7.5 & 3.95 & 3.55 \\
\hline & & & White collar & Employee & Employer \\
\hline & & & 7.5 & 3.75 & 3.75 \\
\hline & & & Official $^{10}$ & Employee & Employer \\
\hline & & & 7.25 & 4.1 & 3.15 \\
\hline
\end{tabular}

Austrian source: Health Care in Transition 2006, Bundesministerium für Health, Familien and Jugend.

(We notice the Austrian different contribution rates for different professions. Here we introduce only the most important. The total rate in the CR is nearly double in comparison with the Austrian case.)

The amount of health insurance contribution does not depend only on the rate of the insurance contribution but also on the contribution base. In the course of Austrian health care reform, it has been proposed (among others) to change the employer's insurance base from gross payments to the value added base ${ }^{11}$.

To find a right proportion between private personal payments and the share of health insurance contribution is as in any other decision-making a very difficult task. Nevertheless, the statistical data show that the more a society is developed, the greater is the total health care expenditure and the greater is also the share of private expenditure. The private expenditure in the Czech Republic will doubtless grow in the future, both voluntary and obligatory, together with development of new technologies of health care, high quality of instruments and growing assortment and efficiency of new remedies (but not only new remedies). In the case of obligatory fees recently confirmed (30 korunas for visit a practitioner, 30 korunas per prescription, 60 korunas per day stay in hospital etc.) the future will show if they have been set right and endurable for low-income categories of patients. In Austria, the low income groups of patients are exempted from prescription fee and from all co-payments. Also pensioners with low pensions, children and students are exempted from fees for treatments by practitioners, out-patient clinics and hospitals. (More details are introduced in the article in Zdravotnické noviny 19/2005). Also, the financial asset of these fees will be revealed. The hospitals know how to estimate the sum relatively exactly, because they have

10 in German: Beamte

11 In detail see Monatsberichte WIFO 7/ 2006: "Finanzierung des öffentlichen Gesundheitswesens". 
experience with the number of patients. In out-patients care some decrease of the number of visits may be expected (the experience of other countries shows a decrease about 10 per cent).

We can here introduce the structure of private costs-sharing in Austria according to services areas: in 2004, the highest share occupied medical service by doctors $(47.5 \%)$, followed by prescription fee $(19.5 \%)$ and therapeutic products $(18 \%)$. Whilst the last share is stable in time, the share of medical services has been decreasing during last ten years, the prescription fee amount has been increasing. It would be useful to introduce the statistical observation of the structure of private cost-sharing in the Czech Republic.

\subsection{The Discrepancy between Growth of Health Care Expenditure and Growth of Financial Sources for Covering It}

The recorded higher long-term growth of the health care expenditure in all observed countries than the growth of GDP ${ }^{12}$, and at the same time the lower growth of sources for covering it, causes the deficit of the health care financial balance and reflects in public finance at all. This development seems to be quite natural and inevitable under conditions where the main sources of finance for health care are the insurance contributions paid at a fixed rate from the wages and salaries whose growth is in long-term lower than the growth of the GDP. Therefore, all countries with this method of financing the health care are obliged to look for further sources of financing on the one hand, on the second hand to look for economy and rationality in spending of the disposable financial sources.

However, in practice the problem of financial deficit of the health care is more complicated by further factors, some of which are particularly significant for the Czech health care and will doubtless influence the growth of the health care expenditure in the future.

In the first place in many documents there is introduced the ageing of the population as the main factor of future growth of health care expenditure. Both the present situation and the future prospect confirm the importance of this factor.

The share of the population aged 65 and over seems to be more favourable in the Czech Republic than in Austria. In 2003, it was $14 \%$ in the CR and $16 \%$ in Austria, nevertheless the development of old-age dependency ratio (number of persons aged 65 and over related to the population of working age 15 to 64 shows a warning picture.

The older population needs more health- and long-term care (for instance, the General Insurance Company pays in average for a forty years aged man about CZK 8,000 yearly, and for an eighty years aged man CZK 39,000).

Two further factors of growing health care expenditure in the future are already mentioned in the first part of this paper: the lag in introducing new technologies and modern technical equipment, the low level of salaries in the field of health care, especially of young doctor and nurses, which contributes to the intention to emigrate by this category of employees.

12 See OECD in Figures 2006. 
These both lags are to be gradually liquidated, what will lead, together with further dissemination of new more efficient but even more expensive medicaments, to improving the situation both in health care and health of the population. To reach these positive effects a huge amounts of financial means will be needed.

Yet other factors of the economic developement influence the health care finance in the field of public sources, among others the rate of unemployment. In the CR, it settled last years in range of $7-8 \%$ and works as factor lowerings the contributions and at the same time needs more sources for the unemployment benefit.

It is difficult to quantify all these factors, because, as all economic indicators they depend on a great number of agents and are very variable in time. There can be only created appropriate conditions for the development in a covetable way. The only factor which will guarantee needed sources of finance for the health care is the positive economic development, and positive results of it (growing incomes of the population and of other sources of finance).

\section{Health Care Reforms}

\subsection{The Aim of Health Care Reforms}

The main goals of the health care reform were worked out many years ago and they are steadily valid not only for the Czech Republic:

- to increase efficiency and economy of the system;

- to guarantee the universal approach to basic health care;

- to maintain solidarity in financing public health insurance and in providing health care; and simultaneously

- to place more emphasis on personal responsibility of an individual, and to integrate the patient as active part of the health care.

These are of course only quite general theses, which would not be disputed by anybody. The difficulty in realizing these tasks in the Czech health care is demonstrated by the fact, that already several proposals of the reform by several governments during last ten years were worked out. Only recently the reform has begun to be in progress ${ }^{13}$ :

- The proposals of reform measures in 2007 - 2010, embracing all main tasks for the providers of the health care, for health insurance funds and defining the new position of the patient as a client, were elaborated.

- The new rights and duties of all concerned institutions and persons in health care will be legally protected by novelization of laws and by elaboration new laws.

- The obligatory fees for prescriptions, for visiting the doctor, for hospitalization were approved, even if this part of reform measures is not difficult to elaborate in the present form, but worse for the realization, and evaluation of the prospective results.

- The both professional and common public have been call up to participate in discussions about health care reform in form of seminars, organized round table,

13 See www.mzd.cz, presentation from the August 10, 2007. 
etc., which is very important for the results of the reform measures and also for common consent with the reform (see "Project Round Table for the future path of healthcare in the Czech Republic" www.kulatystul.cz/en/node/26).

Last time we often hear that the Austrian model of the health care reform could serve as an example for the Czech reform. But also other countries preparing health care reforms are interested in the Austrian case. Accordingly, what are the principles of the Austrian health care reform?

\subsection{Lessons from the Austrian Health Care Reform}

The above introduced data about Austrian health care system attest their relative richness in comparison with the Czech situation, especially in amounts of financial sources which are at disposal to the health care system. Nevertheless, the reform programme, introduced in 1997 deals with some similar problems as the Czech one and this experience may be useful to study.

The main goal of the Austrian health care reforms is the same as of the Czech one: the provision of more efficient and high quality health care, while emphasising the system of prevention.

The distinguished feature of the Austrian reform has been the long-term coherent preparation of it. It started already during eighties and then it was introduced into practice from January 1, 1997. Since this day, the system has been improved and reconditioned, and so far it keeps on developing.

The preparatory works comprised first of all:

- the verification and adoption of the system of indispensable documentation and information;

- the verification of the national catalogue of performances and diagnoses;

- the implementation of the system of controls assuring reformatory measures.

The fulfillment of these tasks created the conditions for further steps of the reform. Unfortunately, neither space nor time was there for fully realization of such preparatory works in the CR.

The planned integration of the Austrian health care system requires a common and comparable diagnoses and services documentation. This is an essential precondition for the coordination of financing the different sectors of the health care, which facilitates the description of the work of doctors with patients both within and outside hospitals. In the in-patient sector there has been uniform documentation for many years, but there is a lack of comparable data from the out-patient sector and from doctors in private practice. Therefore, the creation of a common database on the basis of the uniform documentation of diagnoses and the preparation of uniform service documentation as it exists in the in-patient sector is inevitable.

The creation and introduction of modern electronic systems of information and documentation is advised by working group of experts called „e-Health-Initiative.“ Working areas are digital documentation, communication between all stakeholders, patient safety - and treatment. The advantage of e-technology are: high speed, independence on time and place, security, low cost and unified technological standards. It includes tools for the analysis of data, technical and organizational measures for protection and security of health care data. The central element of the e-health strategie 
is the existing e-card, which provides all needed information about the patient and which is used not only as a pass of identity when visiting a health service, but with help of it every visit by the doctor (every medical service) is electronically registered and to the end of the year every patient gets an overview about all services he has used. It is supposed to include in the future further elements in the e-card system, such as e-prescription, e-medication, invoices and other medical documents, on-line access to health care information. It will organize and improve the communication between the health care staff and the patient. It is expected that until 2015 a communication system will be able to provide important health care data to all competent institutions.

An important reform measure in the year 1997 in the Austrian health care system was the introduction of the Austrian Diagnosis Related Groups System ${ }^{14}$ (DRG) of hospital financing. It concerns the metod of financing the hospitals which are financed by public means. These hospitals have about $73 \%$ of all beds and nurse about $90 \%$ of the patients. It means that their role in health care is decisive.

The in-patient care in Austria is - as in the Czech Republic- the largest and most costly segment of the health care, drawing about $50 \%$ of the total financial means for health care. Before introducing the new system, the hospitals were financed with a daily flat rate, what did not contribute to the economy of the financial means, because hospitals were not interested in lowering the number of days, and consecutively number of beds. The DRG system changed the situation.

The Austrian DRG system is a case of fee payment system based on modified diagnosis related groups. At present cca 890 diagnosis groups are at disposal. The currently valid reimbursment system in the in-patient sector differentiates between two financing areas: the nationally uniformed DRG core area, and the DRG fund control area, which can be varied by the individual Lands. The units of calculations used are points. In the core area of the Austrian DRG model, the basis for the awarding of points for an in-patient stay are procedure- and diagnosis-oriented case groups including all special scoring rules. At present cca 890 diagnosis groups are to disposal. Every diagnosis group gets a time of hospitalization. Prolongation or abridgement of this time results in deduction or surcharge of the scoring. A nationally uniform number of points is allocated for stays in intensive care units, for acute neurological aftercare, for geriatric care and for services in the psychiatric day care sector. Special rules apply for lengths of stay above the upper bound or below the lower bound.

The core area has been continuously further developed since 1997, updated and subjected to annual revisions. In the years 1999 and 2000, the DRG flat rates were recalculated together with selected reference hospitals, and the results were included in the model for 2002. Since then the Austrian DRG model has remained basically unchanged in the core area - apart from some minor changes which were required from a medical or economic perspective.

For the Austrian DRG models 1997-2001, the number of points for the DRG flat rates was determined on the basis of around 500,000 inpatient stays and costs calculated in 20 reference hospitals. This scoring system was updated as part of the project "DRG recalculation" and has been in use since the 2002 Austrian DRG model.

14 in German LKF = Leistungsorientierte Krankenanstaltenfinanzierung 
The fund control area of the Austrian DRG model can be modified by individual Lands and enables them to also take structural criteria into account. By means of appropriate modification of the fund control area, different levels of hospital personnel and equipment of individual Lands (resulting, for example, from varying mandates to secure care) can be considered in the performance-orientated distribution of funding from State Health Funds.

The system ${ }^{15}$ contributes doubtlessly to the improvement of the health care cost calculation. The existing results of DRG system are positive - the number of beds is decreasing and a part of patients is transfered to the out-patient sphere. But there are some voices speaking about the danger of worsened health care and as the consequence the worsening of the health. This means that it will be necessary to control the effect of this measure not only on costs, but on the health of the patient.

The health care reforms in Austria continue in order to ensure the feasibility of long-term financing the growing demand for health services. A system of reform measures was introduced in 2005.

They are focusing mainly on elimination of two weaknesses of the system:

- the lack of integrated strategy and planning going beyond the regional border,

- a dual financing system concerning the financing of hospitals and out-patient areas, which have caused the uncoordinated development of this two sectors.

These two structural weaknesses should be eliminated during the period 2005 2008 , on the ground of concluded agreement between the provinces and government.

To ensure the main goal of Austrian health reforms, which are efficiency and quality of the system, many legal, organizational and financial measures have been recently introduced.

The division of competencies forseen in the federal constitution is as follows: the area of social insurance is the responsibility of the federal government, both with regard to legislation and implementation. In the hospital sector, the federal government is only responsible for the basic legislation, and the provinces are solely responsible for the provision of care. With the aim of ensuring coordinated actions in the health care system, the federal government and the provinces conclude a treaty every four years, through which the existing laws are amended or new passed.

In order to institutionalize the cooperation between the main bodies financing the health care (insurance, federal government and provinces) the Federal Health Agency and the Provincial Health Fund as separate legal entities should be established to jointly plan and control the Austrian health care system.

The growing demand for health care services and intended introduction or extension of some kind of services like prevention programmes, promotion of the transplantion programmes, financing of planning and projects, financing of improvements of the documentation system, calls for additional financial means. Many measures in the field of securing additional financial means for health care have been introduced and others are looking for: besides economical measures and savings (reducing administrative costs in

15 More details of the Austrian DRG model are published in "Health Care in Transition"

"LKF-Systembeschreibung" (DRG - Description of the System) Bundesministerium für Gesundheit und Frauen, and M.M. Hofmarcher, Herta M. Rack: "Health System in Transition", Vol. 8, No. 3 2006, Chapter 5, Part 5.2, Chapter 6. Austria Health System Review, WHO 2006. 
the system, avoidance of paralel services, etc.) an additional income is assumed to come from the federal government from increase of tobacco tax (0.14 EUR per 1 packet of cigarettes), from increase of health insurance contributions by $0.1 \%$, some increase of prescription fees and other co-payments. The last three kinds of additional sources will be paid immediatelly from pockets of the population.

The listed measures are to be re-evaluated every two years.

It will be useful to study the consolidation measures in the health insurance system, which create part of the Austrian reform. Especially cost, mark-up, and price control measures introduced by law and monitoring system established in the statutory social insurance scheme. Also new sources of income were found and used: short-term loans, and a part of money from increased taxes on tobacco products.

The Austrian reform supposes further cost sharing by patients and economy in medicaments spending, which are also topical tasks of the Czech health care reform. On the other hand, any increase in health insurance contribution rates in the Czech conditions cannot be enforced.

The reform of the Austrian health care system is continuing on the ground of achieved experience in the course of providing it.

\section{Conclusions}

In this paper presented insight into the health care problems discloses great complexity and difficulty in looking for ways how to solve the lack of financial sources for balancing the deficit of the system, consisting in growing needs of the society for health care and growing offer to cover the demand, but on the other hand in growing lack of means to cover it.

The status of the Czech health care approaches the developed Austrian system, as it was shown when comparing the health status of the population and the health care basis in both countries. However, the need to improve the system is a topical task for both countries and also for other countries both of the Western and Eastern Europe.

From the point of view of financial sources for health care there are many differences in Austria and the Czech Republic. The participation of the patients is remarkably higher in Austria (about 30\% included investment) than recently in CR (12.8\%). The Austrian reform supposes further cost sharing by patients and economy in medicament spendings, what are also topical tasks of the Czech health care reform. On the other hand, the insurance rate is much higher in CR. It means that evaluating the disponible sources for covering the health care expenses and considering their changes we must take into account both the extend of cost sharing and the rate of insurance fee.

Another dissimilarity is in paying the health insurance for the children and other non employed members of the household. In the Czech Republic, their insurance is paid from the state budget, in Austria, it is paid from the insurance of the employed members of the family.

The topical task is to find right ways how to economize financial means which are at disposal and to look for new sources. We must take into account that costs of the health care in the $\mathrm{CR}$ will continue to grow faster due to the lag in growing reimboursement of the staff in health care sector, the lag in introduction of new technologies and also for the reason that the reform steps are in delay in comparison with Austria. Also such expenses 
as for creating an integrated documentation system, financing the preventive programmes, financing the projects, etc. will call for the increase of the financial means in a greater degree than hitherto. From this point of view it would be useful to ask for cost sharing at the EU, of course on the basis of good projects.

\section{References}

Berichte über die soziale Lage 1997, 1998, 1999, 2002, 2003. Wien : Ministerium für Arbeit, Gesundheit und Soziales.

Sborník textů k otázkám zdravotnictví (2001), č. 9. Praha : Centrum pro ekonomiku a politiku [Centrum for Economics and Politics, collection of scripts on health care, No. 9/2001].

Czech Health Statistics Yearbooks 1999 - 2004. Prague : ÚZIS.

Durdisová, J. (2001), Úvod do teorie zdravotní politiky. Praha : Vysoká škola ekonomická.

Der Donauraum (2005), "Gesundheitsreformen in Mittel- und Osteuropa, Nr. 2.

Guger A., Marterbauer M., Walterskirchen E. (2006), "Finanzierung des öffentlichen Gesundheitswesens". WIFO Monatsberichte, Nr. 7.

Gesundheit und Krankheit in Österreich, Gesundheitsbericht (2004). Wien : Österreichisches Bundesinstitut für Gesundheitswesen.

Health Care and Health Services in the Czech Republic 2001. Prague : Institut of Health Information and Statistics of the Czech Republic.

Hofmarcher, M. M., Rack, H. M. (2006), "Austria: Health system review". Health Systems in Transition, 8 (3), pp. 1-247.

Jahrbuch der Gesundheitsstatistik 2003, 2004.

OECD (2005), Health at a Glance. OECD Indicators 2005.

OECD, Health data 2006.

OECD (2003), "Health Systems: Making them Fitter". Observer, July.

Social Protection Systems in Austria, Health Care (2003). Vienna : Federal Ministry of Social Security, Generations and Consumer Protection.

Stabilizace a reforma českého zdravotnictví (2007). Praha : Ministerstvo zdravotnictví ČR, www.mzd.cz [Stabilization and Reform of the Czech Health Care].

Streissler, A. (2004), Das Oesterreichische Gesundheitswesen. Eine oekonomische Analyse aus interessenpolitischer Sicht. Wien : Kammer für Arbeiter und Angestellte für Wien.

Vavrejnová, M. (2005), "Z kapes pacientů: ano či ne, kolik...". Zdravotnické noviny, č. 19 [From the Pockets of Patients: Yes or Not, How Much...].

Vepřek, J., Vepřek, P., Janda, J. (2002), Zpráva o léčení českého zdravotnictví aneb Zdravotnická reforma včera, dnes a zitra. Praha: Avicenum [Report about the Treatment of the Czech Health Care].

www.kulatystul.cz.

Zdravotnictví České republiky 2006 ve statistických údajích. Praha : ÚZIS [Health Care of the Czech Republic in Statistical Data].

Zdravotnictví jako součást národní ekonomiky 2005. www.uzis.cz [Health care as a part of National economy 2005]. 